\title{
PULSED MODE EVALUATION OF AN AXIAL GEOMETRY CESIUM SPUTTER MEGATIVE ION SOURCE*
}

\author{
G. D. Alton and C. M. Jones \\ Oak Ridge National Laboratory \\ Oak Ridge, Tennessee 37831
}

CONF-850470--2

DE85 013635

An axial geometry negative ion source has beeri evaluated as a source of pulsed negative ion beams for possible future use of the Holifield Heavy Ion Research Facility (HHIRF) tandem accelerator as a synchrotron injector. During test stand operation and HHIRF tandem accelerator testing, inigh-intensity, square wäve-form, $100 \mu \mathrm{s}$ wide, pulsed beams of $\mathrm{Ag}^{-}, \mathrm{Au}^{-}, \mathrm{Cu}^{-}, \mathrm{Ni}^{-}$, and $\mathrm{O}^{-}$were produced at peak intensity leveis ranging between 100 and $350 \mu \mathrm{A}$. The beam intensities were observed to increase approximately linearly with pulsed voltage amplitude over a range of voltages between 400 and $2400 \mathrm{~V}$. In most cases, the pulsed and d.c. beam components were found to be essentially independent of each other, i.e., the d.c. component could be adjusted without significantly affecting the pulsed component. Pulsed 160- beams at peak intensities of $100 \mu \mathrm{A}$ were injected into the HHIRF tandem accelerator without observable effects on the operational stability of the accelerator.

*Research sponsored by the Division of Basic Energy Sciences, U.S. Department of Energy, under contract DE-AC05-840R21400 with Martin Marietta Energy Systems, Inc. 


\section{Introduction}

Our interest in developing pulsed mode negative ion sources has been stimulated by consideration of a synchrotron-cooler ring as a possible addition to the Holifield Heavy Ion Research Facility (HHIRF) and by consideration of a heavy ion collider facility for which the HHIRF tandem accelerator would serve as an injector. In this paper, we report on an initial effort to develop and evaluate negative ion sources and the associated pulsing technology required for injection into such accelerators. Specifically, we have evaluated the performance of two existing negative ion sources for pulsed mode operation and performed an initial operational test of the HHIRF tardem accelerator with an intense pulsed ${ }^{160} 0$ beam.

Typical pulse widths and repetition rates for synchrotron injection applications are $\sim 100 \mu \mathrm{sec}$ and a few $\mathrm{Hz}$, respectively. The peak beam . currents desirable for synchrotron injection (several hundred microamperes) exceed d.c. ion beam intensities available from most sources of heavy negative ions. However, it is known from previous work at the Brookhaven National Laboratory that such pulsed beam intensities can be produced for a limited number of elements with high electron affinities and that large, low duty-cycle beams can be injected into MP type tandem accelerators without detrimental effects.[1]

\section{Source Selection}

The improved radial and axial geometry negative ion sources, both of which are described in these proceedings, $[2,3]$ were each evaluated in terms of their pulsed negative ion beam capabilities. Negative ions are generated in these sources by cesium ion sputtering of a probe containing 
the material of interest which is biased negative by 1 to $3 \mathrm{kV}$ relative to the source housing. The probe potential is maintained at a d.c. bias level for standard operation and a combination of d.c. and superposed pulsed potentials from a pulse generator for pulsed mode operation. With this arrangement, a d.c. beam of modest intensity ( $<1 \mu \mathrm{A}$, typically) can be generated for tandem terminal voltage control and as a beam for adjustment of beam line transport components (lenses, steerers, etc.) to assist in transmission of the superposed pulsed beam through the accelerator and beam transport system.

Preliminary testing of the radial and axial geometry sources showed the distinct superiority of the axial geometry source for pulsed-mode generation of $\mathrm{Au}^{-}, \mathrm{Ni}^{-}$and $\mathrm{Cu}^{-}$negative ion beams. During testing, the pulser amplitude was $1.2 \mathrm{kV}$ with a pulse width of $\sim 100 \mathrm{usec}$ and a repetition rate of $10 \mathrm{~Hz}$. Peak negative ion pulse intensities from the radial geometry source for the indicated elements were typically $\sim 80 \mu \mathrm{A}$ while those from the axial geometry source were higher. Therefore, the axial geometry source was selected as the source for pulsed mode generation of negative ion beams.

The axial geometry source is the second generation of a similar source, designed and developed in 1978. [4] As shown in Fig. 1, the mechanical design features of the revised source have been significantly improved and the source exhibits rather different performance characteristics. The present source utilizes a solid tungsten annular ionizer with a 
noninductively-wound tungsten heater instead of the helically-wound tantalum heater which was used in the original source for producing the positive cesium ion beam used to sputter the material of interest. This ionizer offers a simple but well-defined ion generation surface which is more amenable to numerical analysis. Such calculations predic: concentrated positive ion wear pattern surrounded by a weak halc in contrast to strong halo effects often present in ion sources which use helically wound ionizers. Of course, the halo beam can be eliminated in such sources by appropriate choice of the sample size. In the annular ionizer source, ions are generated and extracted from the inner surface of the ionizer; all other heated surfaces are obscured from the ionizer/probe electric field region of the source. Consequently, the observed sputter wear pattern exhibits, exactly as predicted, a weak halo surrounding the axially located concentrated wear region.

The geometric configuration of the ionizer/sputter probe region of the source is readily amenable to simulation by solving Poisson's equation numerically. Computer assisted design techniques were employed by per forming detailed calculations of the positive and negative ion trajectories through the electrode system. The Stanford Linear Accelerator Center electron trajectory computer code[5] was used for these computations. An example of the trajectories for positive ions extracted from the annular ionizer surface and accelerated to the sputter probe is shown in Fig. 2. The resulting positive ion current density distribution at the probe surface is shown in Fig. 3. Figure 4 displays the corresponding negative ion 


\begin{abstract}
$-5-$
trajectories from the sputter probe through the anode aperture of the source; the negative ion beam is assumed to the fully space charge compensated. In general, there will be a net positive space charge potential in this region of the source due to the large positive ion current. However, due to the differences in particle velocities in the anode and cathode regions of the source, differential space charge effects can affect the beam in these regions of the source. This effect may be important for the pulsed mode of operation because of the very high negative ion beam currents which can be generated.
\end{abstract}

\title{
3. Experimental Arrangement
}

Pulsed mode operation and testing of the negative ion sources were performed at a negative ion source test stand. The test stand consists of a turbomolecular pumped ion source and beam transport vacuum housing, and an off-ground platform which houses the pulse generator, d.c. probe and ionizer power supplies. The facility is not equipped with provisions for mass analysis. The platform is typically operated at a potential of - $20 \mathrm{kV}$. The negative ion beams extracted from the source were focused by means of a conventional einzel lens into an electron suppressed Faraday cup located $1 \mathrm{~m}$ from the source exit aperture. The pulsed negative ion beam intensities were measured using a conventional storage oscilloscope with a $10 \mathrm{k} \Omega$ precision resistor in parallel with the $1 \mathrm{M} \Omega$ input of the oscilloscope. A schematic electrical diagram of the power supply arrangement used during these tests is shown in Fig. 5. As indicated, the source housing was biased positive relative to the sample probe by superposition of the output from the pulse generator and a d.c. power supply. With this 
arrangement the pulsed and d.c. beam components could be controlled independently.

4. The Pulse Generator

The pulse generator used throughout the evaluative tests was procured commercially.[6] The measured wave form of the pulse generator output, taken at a pulse width of $\sim 100 \mu \mathrm{sec}$ and repetition rate of $10 \mathrm{~Hz}$ is shown in Fig. 6. Because of the pulse height droop, the pulsed negative ion beam will also exhibit a similar shape due to the approximately linear dependence of the sputtering process on ion energy in this energy regime.

5. Negative Ion Yields

The negative ion yields from the axial geometry source were found to approximately vary linearly with pulse voltage amplitude and, in most cases, the pulsed amplitude and dc amplitude were found to be essentially independent of each other, i.e., the d.c. beam could be reduced without affecting the amplitude of the pulsed component. This independence is very important in practice, because a weak d.c. beam component is desirable for control and monitoring of trie accelerator while transmitting the largest possible pulsed beam component through the accelerator and beam transport system for synchrotron applications.

The dependence of peak negative ion beam intensities on pulsed voltage amplitude is shown in Fig. 7. As indicated, the negative ion yields increase linearly for peak pulse voltages above $\sim 400 \mathrm{~V}$. From these results, one would expect much higher negative ion yields with increased 
pulse generator output voltages. However, the negative ion yield will ultimately reach a maximum and begin to decrease with further increase in pulse voltage amplitude. Future tests will include operation of the source at pulse voltage amplitudes up to $4000 \mathrm{~V}$.

During testing, the pulse generator was operated at $1.2 \mathrm{kV}$ with a pulse width of $100 \mu \mathrm{sec}$ and a repetition frequency of $10 \mathrm{~Hz}$. Examples of $\mathrm{Au}^{-}, \mathrm{Cu}^{-}$and $\mathrm{Ni}^{-}$spectra measured under these conditions are shown in Fig. 8. Since the test stand is not equipped with provisions for mass analysis, care was taken to sputter-clean the samples thoroughly at d.c. probe voltages of $-1000 \mathrm{~V}$ to $-1500 \mathrm{~V}$ over protracted periods of time in order to remove residual oxide layers. This procedure was adopted to eliminate or reduce contaminant beam contributions to the respective spectra to negligible proportions. The intensities of momentum analyzed beams of $\mathrm{Ni}^{-}$observed during a preliminary test of the HHIRF tandem accelerator were sufficiently close to those shown in Fig. 8 to render confidence in the elemental purity of the spectra acquired during test stand operation.

\section{Injection into the Tandem Accelerator}

High-intensity pulsed ${ }^{16} 0^{-}$beams were injected into the HHIRF tandem accelerator in order to evaluate operation of the accelerator in this mode. Parameters chosen for this evaluation were pulse length $100 \mathrm{us}$, repetition rate $8 \mathrm{~Hz}$, and average pulse amplitude $100 \mu \mathrm{A}$. A $6 \mu \mathrm{g} / \mathrm{cm}^{2}$ carbon terminal foil stripper and a terminal potential of 14.1 MV were chosen for the evaluation. Examples of the injected $160-(300 \mathrm{keV})$ and accelerated ${ }^{16} 0^{6+}$ (99 meV) beams are shown in Fig. 9. No evidence of voltage instabilities 
or terminal voltage droop were detected during these tests. However, the percentage transmission of the pulsed component of the beam was observed to be slightly lower than that of the d.c. component, indicating perhaps the presence of space charge effects which are expected during low-velocity transport of high-density negative ion beams in the injector. We also noted that transport of pulsed beams through the injector and to the accelerator required slightly increased lens potentials over those required for transport of d.c. beams.

\section{Conclusions}

The axial geometry source has proven to be an excellent source for pulsed mode operation, producing high intensities of negative ion beams from a spectrum of elements. The absence of any observable deleterious effects during operation of HHIRF tandem accelerator with intense pulsed ${ }^{16} 0$ beams indicates that the tandem accelerator can be effectively used as a synchrotron injector. 


\section{References}

[1] P. Thieberger, M. Mckeown, and H. E. Wegner, IEEE Trans. Nucl. Sci. NS-30, No. 4 (1983) 2746 .

[2] G. D. Alton, R. M. Beckers, and J. W. Johnson, these proceedings, .

[3] G. D. Alton, these proceedings, $p$.

[4] G. D. Alton, IEEE Trans. Nucl. Sci. NS-26, No. 3 (1979) 3708.

[5] W. B. Hermannsfeldt, SLAC Report 166 (1973).

[6] Velonex Corporation, Santa Clara, California.

\section{DISCLAIMER}

This report was prepared as an account of work sponsored by an agency of the United States Government. Neither the United States Government nor any agency thereof, nor any of their employees, makes any warranty, express or implied, or assumes any legal liability or responsibility for the accuracy, completeness, or usefulness of any information, apparatus, product, or process disclosed, or represents that its use would not infringe privately owned rights. Reference herein to any specific commercial product, process, or service by trade name, trademark, manufacturer, or otherwise does not necessarily constitute or imply its endorsement, recommendation, of favoring by the United States Government or any agency thereof. The views and opinions of authors expressed herein do not necessarily state or reflect those of the United States Government or any agency thereor. 
Figure Captions

Fig. 1. The axial geometry cesium sputter negative ion source.

Fig. 2. Calculated positive ion trajectories in the ionizer/sputter probe region of the source.

Fig. 3. Calculated positive ion current density distribution at the sputter sample surface.

Fig. 4. Calculated negative ion trajectories in the ionizer/sputter probe regions of the source resulting from the positive ion current distribution shown in Fig. 3. Full space charge compensation is assumed.

Fig. 5. Schematic electrical diagram of the power supply arrangement used to produce superposed d.c. and pulsed negative ion beams.

Fig. 6. The measured waveform of the pulse generator.

Fig. 7. The dependence of peak negative ion yields on pulsed voltage amplitude.

Fig. 8. Waveforms of negative ion beans produced by the axial geometry source operated in the pulsed mode.

Fig. 9. Waveforms of ${ }^{16} 0$ beams injected into and accelerated by the Holifield Heavy Ion Research Facility tandem accelerator. 

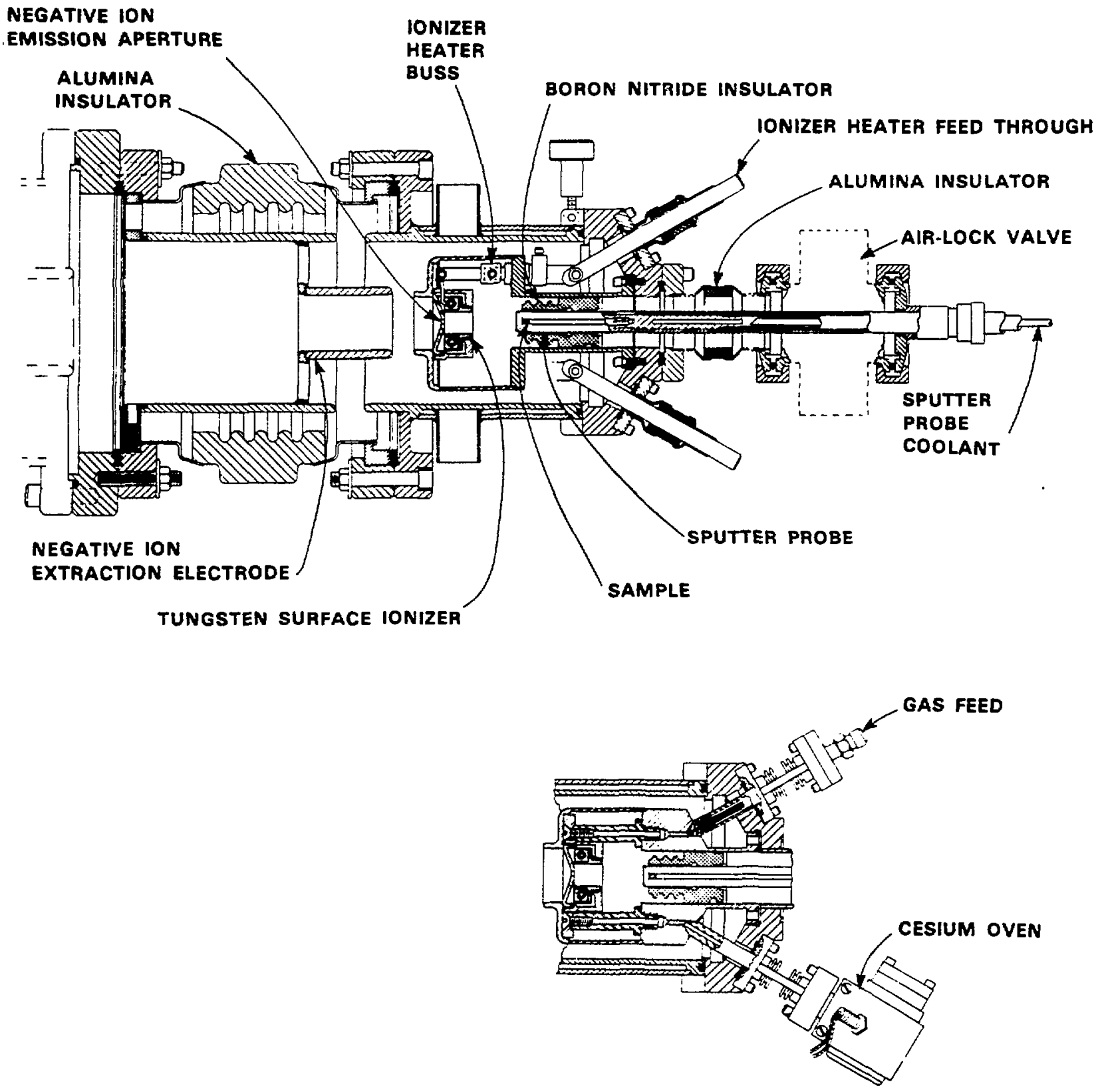


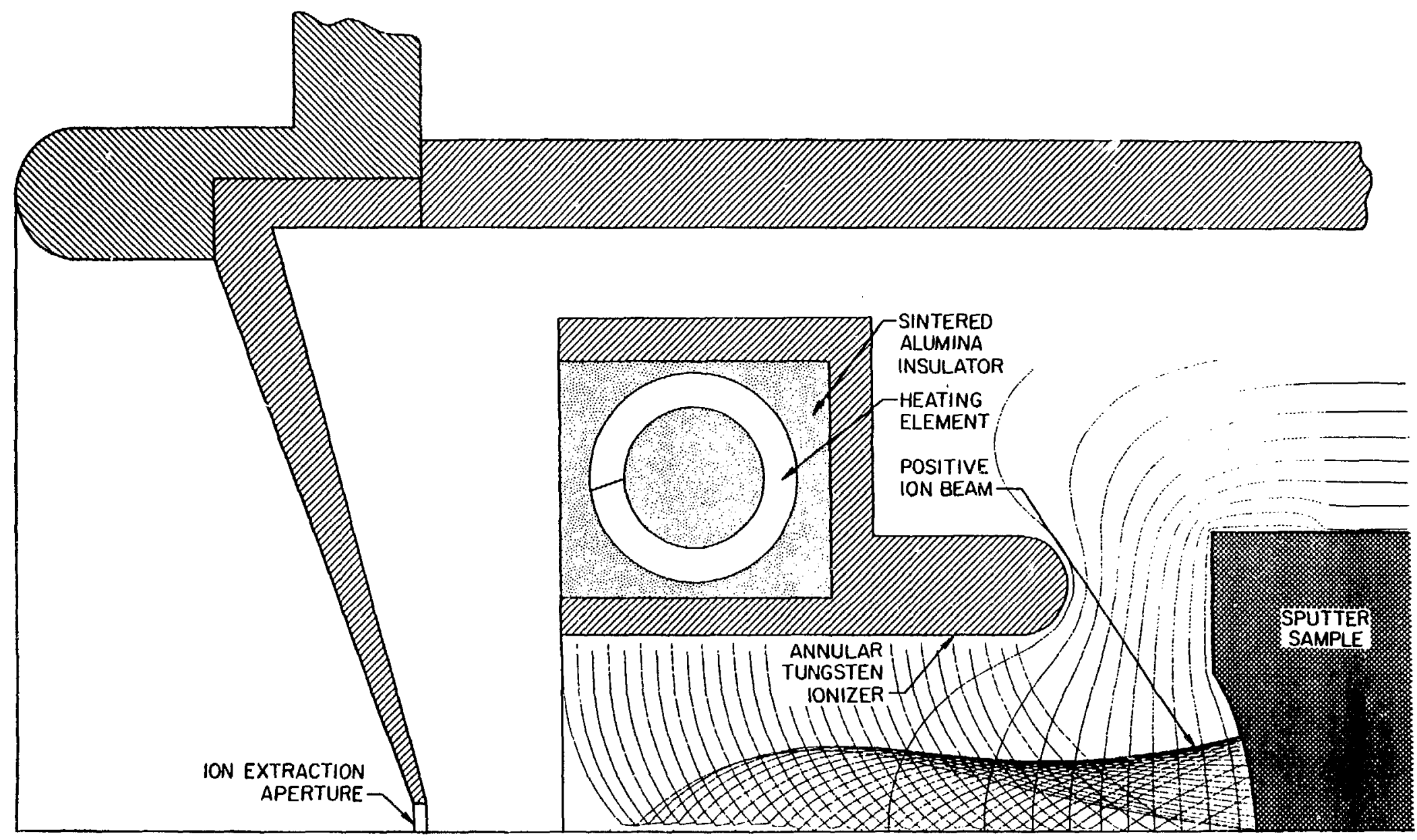




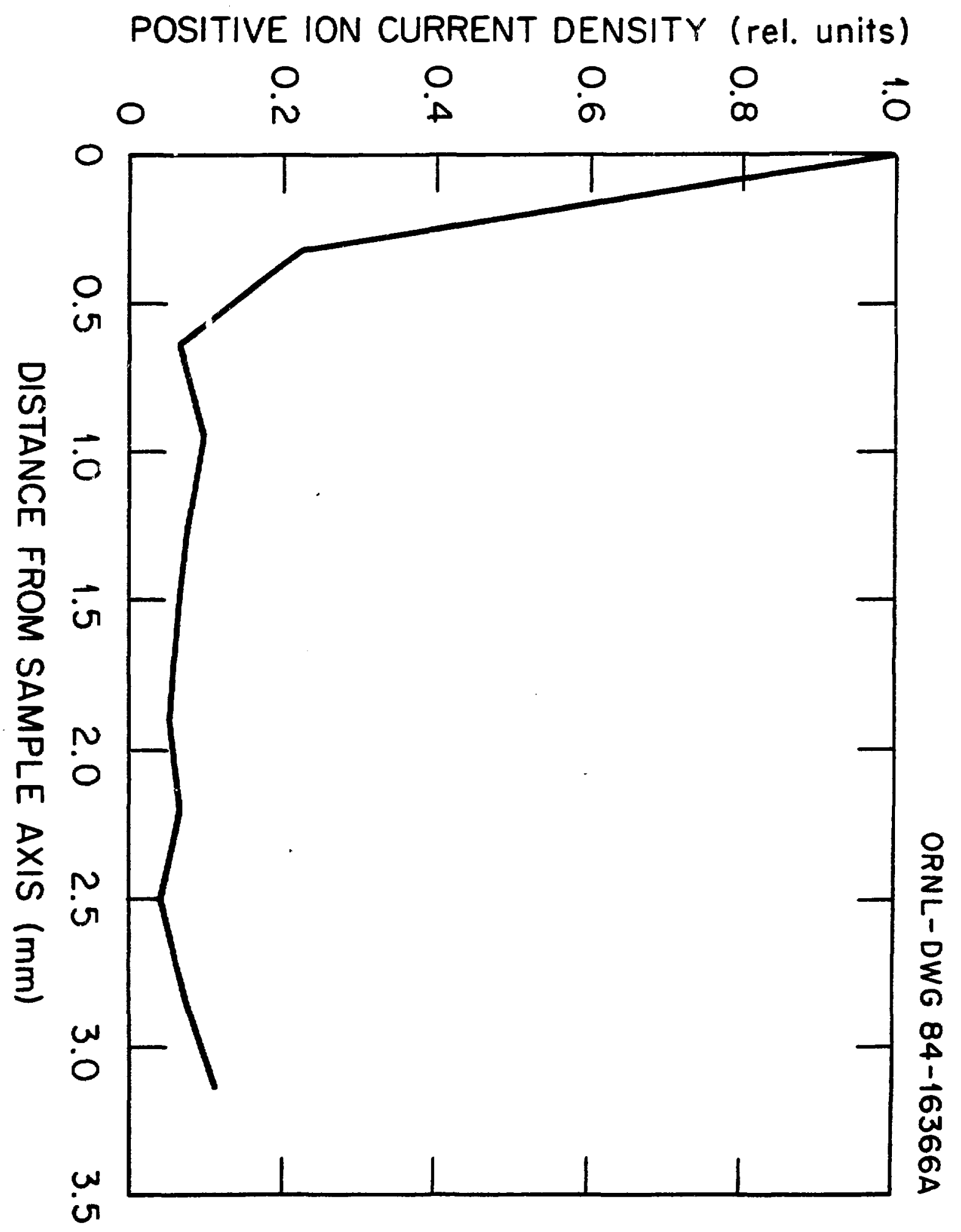




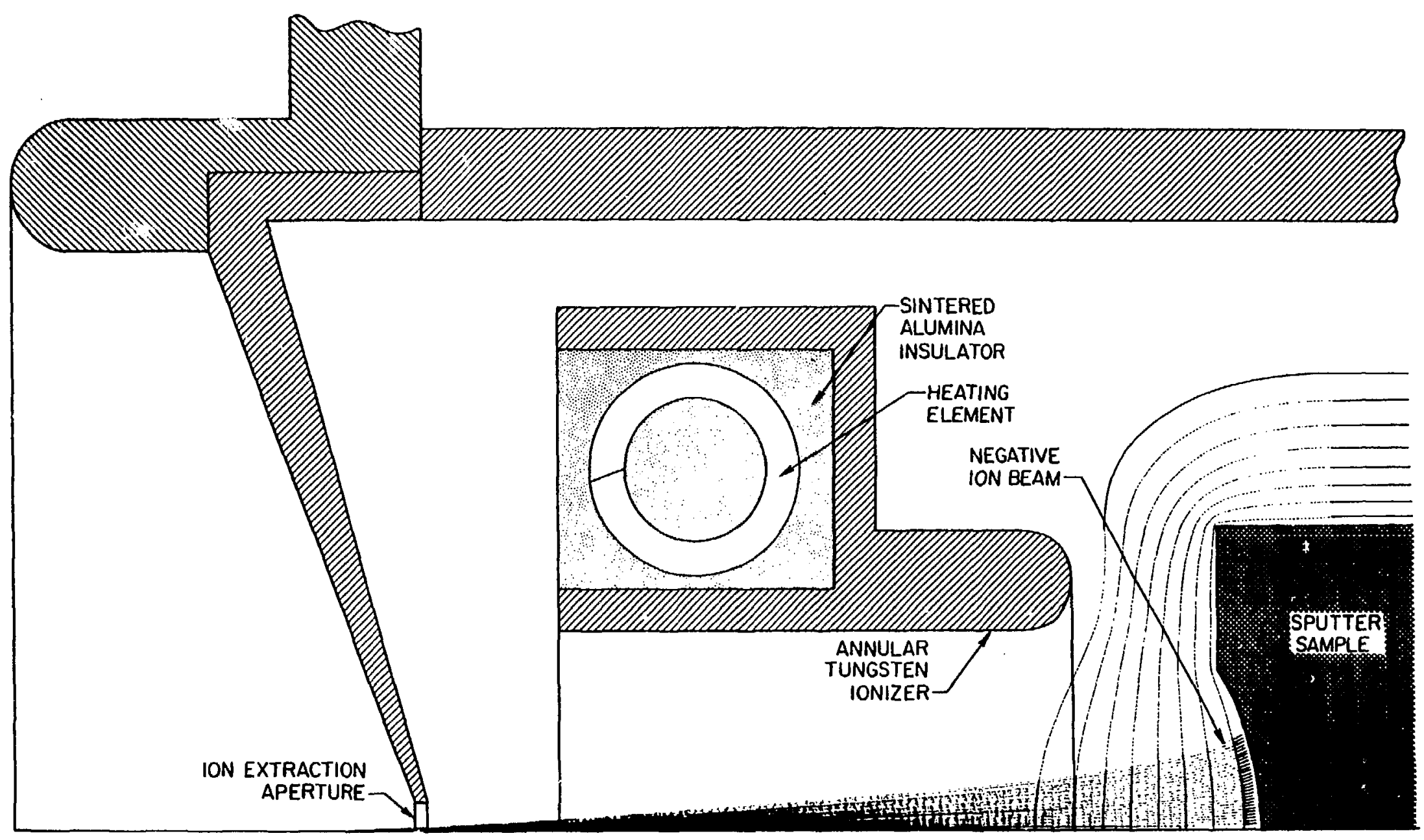



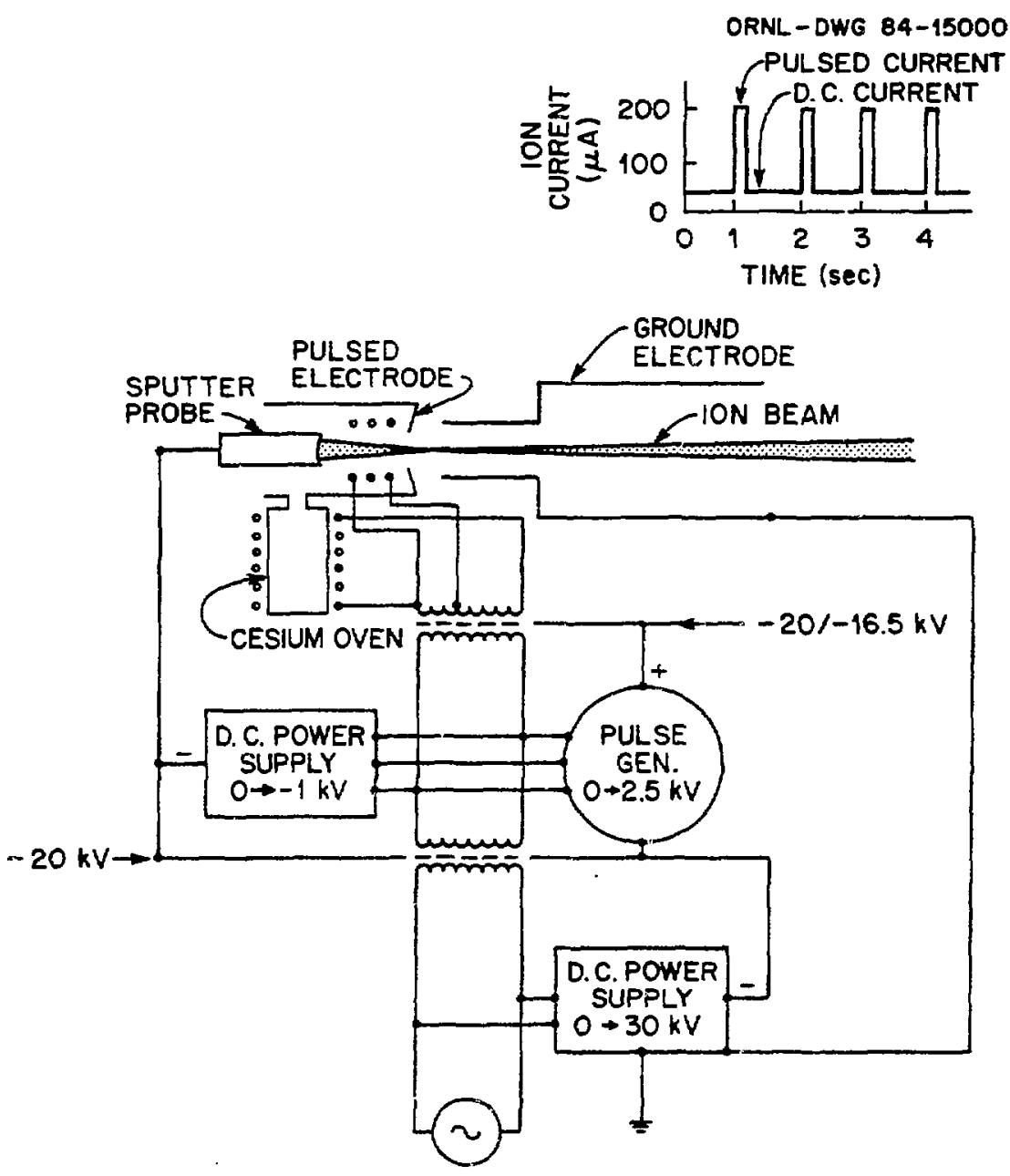
PULSE AMPLITUDE:

$5 O \mathrm{~V} / D I V I S I O N$

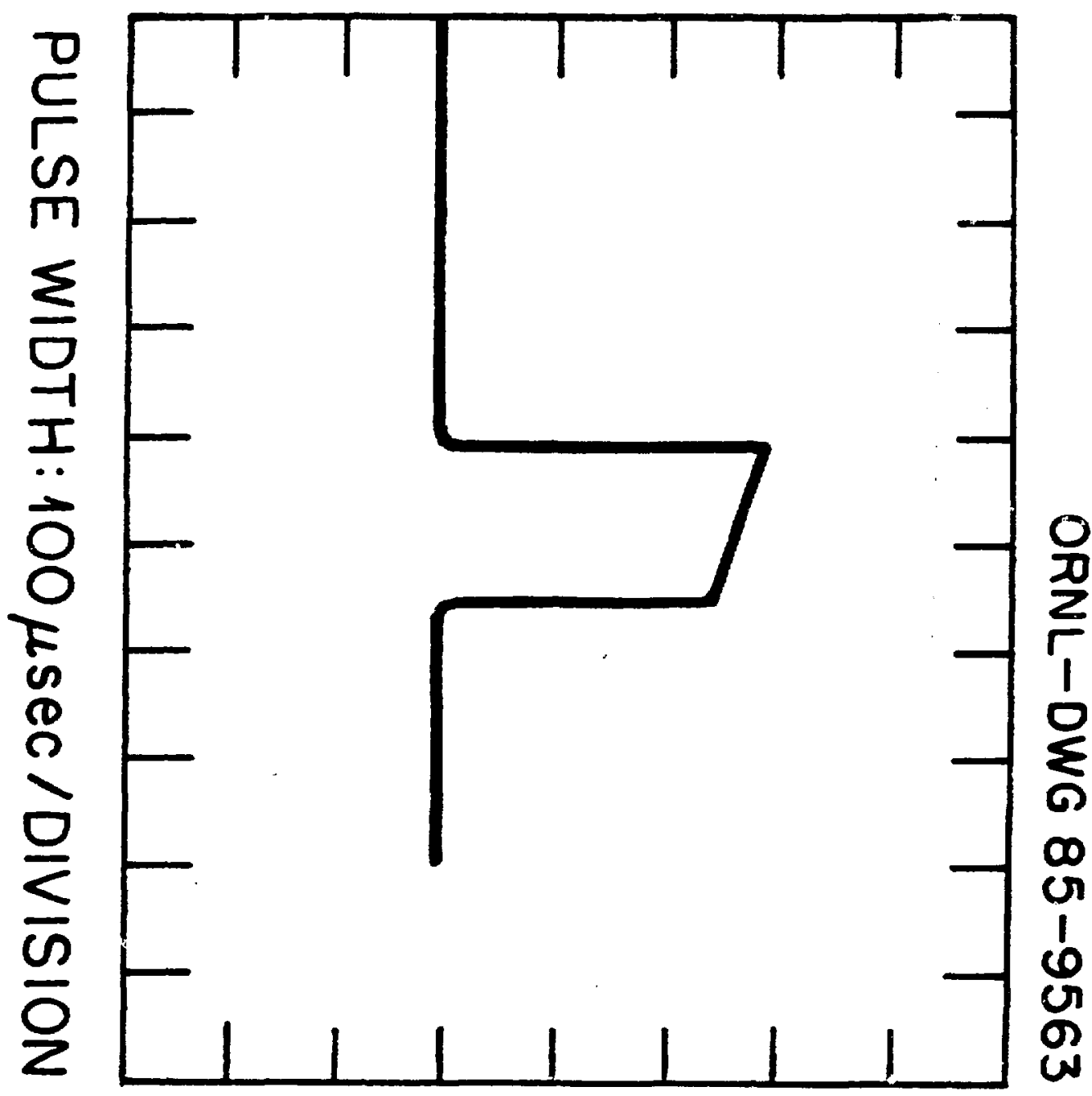




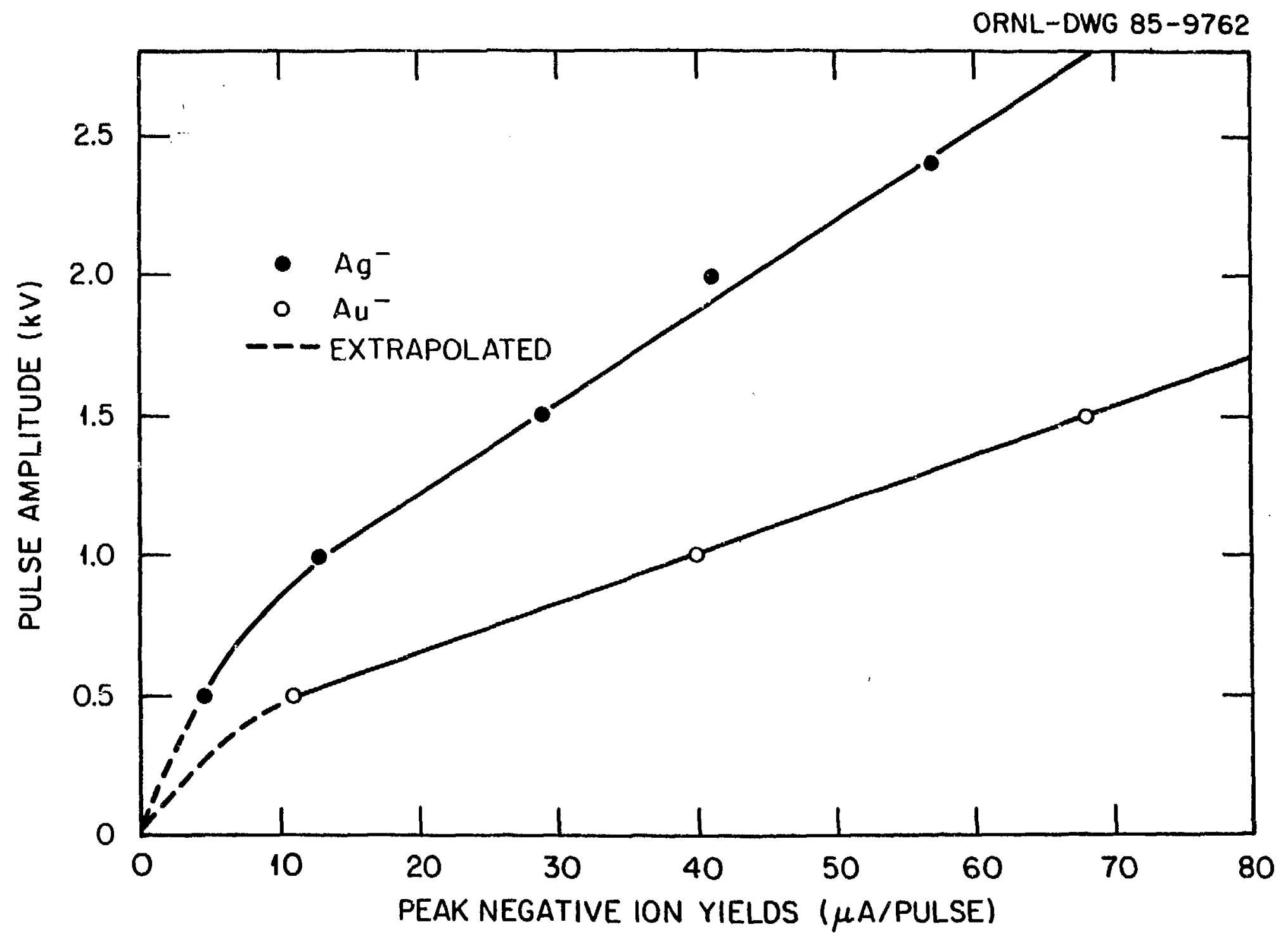


ORNL-DWG 84-14999

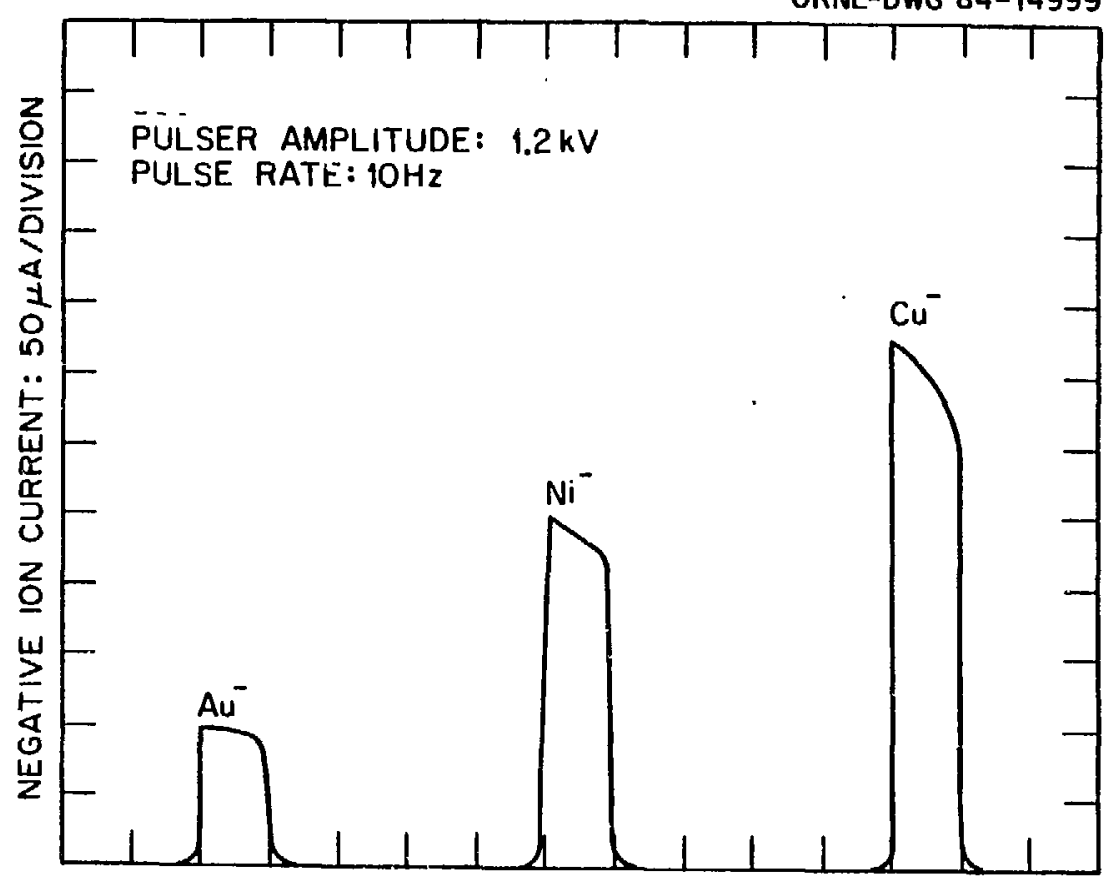

PULSE WIDTH: $100 \mu \mathrm{sec} / D I V I S I O N$ 
ORNL - DWG 85-9856

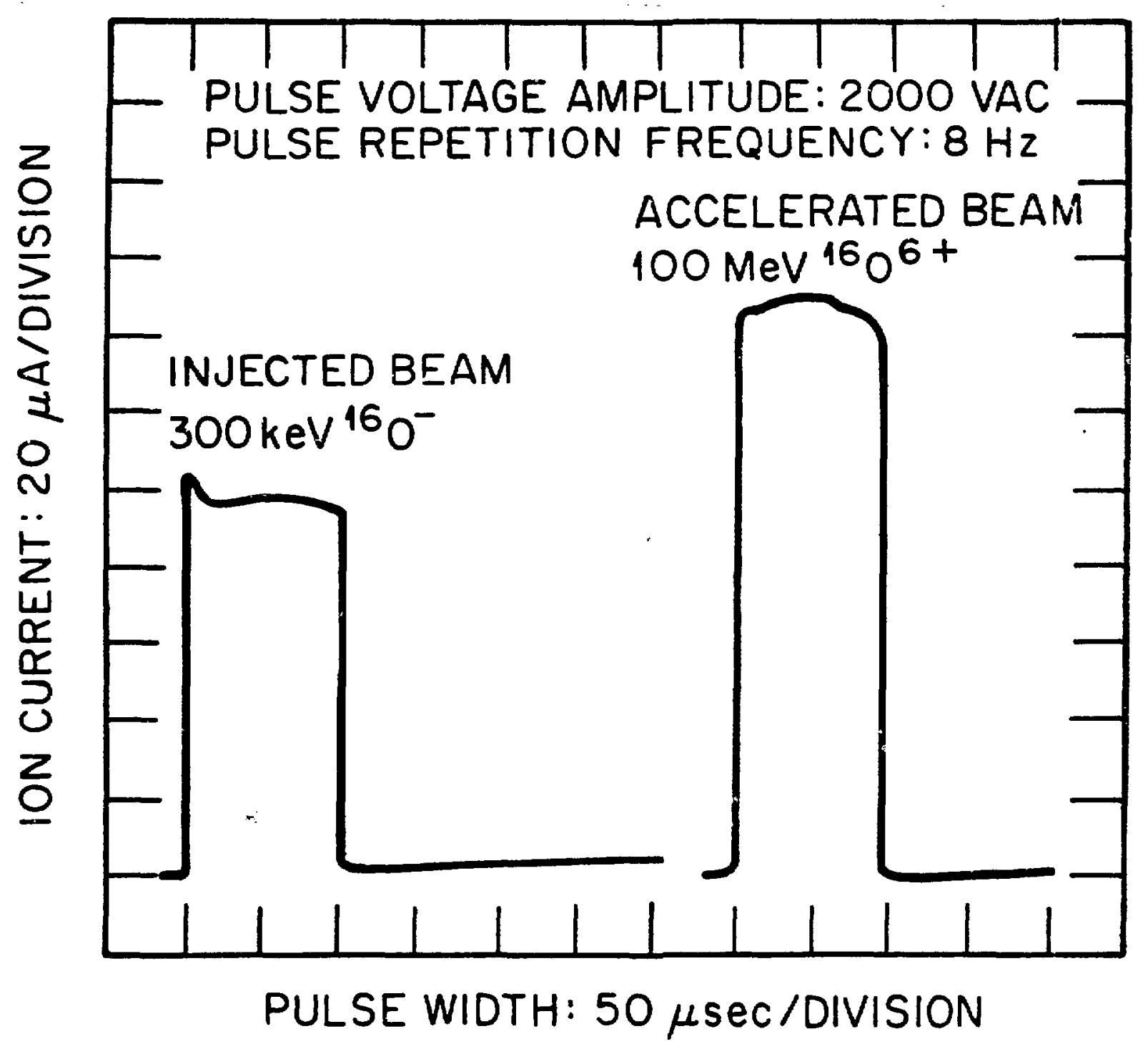

